\title{
BIODIESEL FROM MICROALGAE USING SYNTHESIZED NOVEL ALKALI CATALYST
}

\author{
CerCado, A. P. I. ${ }^{1,2^{*}}-$ BAllesteros, F. C. ${ }^{2}-$ CAPAREDA, S. C. ${ }^{3}$ \\ ${ }^{I}$ College of Engineering and Architecture, Capiz State University \\ Roxas City, Capiz, Philippines \\ ${ }^{2}$ Department of Environmental Engineering, University of the Philippines Diliman \\ Quezon City, Philippines \\ ${ }^{3}$ Biological and Agricultural Engineering Department, Texas A\&M University \\ College Station, Texas, USA \\ *Corresponding author \\ e-mail: cercadopaulo@gmail.com
}

(Received 21 ${ }^{\text {st }}$ Jun 2017; accepted $26^{\text {th }}$ Sep 2017)

\begin{abstract}
The aim of the study is to be able to create a solid catalyst that would be sourced from cheap materials, inexpensive to produce, and can comparatively produce high FAME yields in transesterification reactions involving microalgae as lipid source. The impregnation method was used to synthesize the catalysts Li-pumice, K-pumice, and Na-pumice. The synthesis parameters were varied at different solution concentrations to determine which created the best performing catalyst in the transesterification process. Catalyst characterization was evaluated using Hammett indicators, Scanning Electron Microscopy (SEM), Energy-dispersive X-ray Spectroscopy (EDS), and Infrared Spectroscopy (IR). The catalyst was easily separated by filtration and further investigation proved that it can be reused multiple times in transesterification processes. The best performing catalyst was observed to be K-pumice and the optimum concentration of the contact solution in the synthesis was $1.0 \mathrm{~N}$. The transesterification reaction was able to generate an optimum of $77 \%$ Fatty Acid Methyl Ester (FAME) yield when process parameters were: reaction temperature $=60{ }^{\circ} \mathrm{C}$; methanol to oil ratio $=18: 1$; catalyst load $=10 \%$; and reaction time $=2$ hours. The results were able to prove that effective catalyst for biodiesel production can be sourced from cheap materials such as pumice and that the preparation of such can be done in a fast and cost effective manner. It is encouraged that more cheap materials should be investigated for catalyst synthesis that would become ideal for biodiesel production.
\end{abstract}

Keywords: bioenergy, pumice, synthesis, transesterification, yield

\section{Introduction}

The spike in the demand of fuel globally and the realization that fossil fuels will be depleted in the near future had caused scientists and opportunists to look for an alternative. For years, researchers have gone back investigating biofuels as the alternative in the exhaustion of fossil fuels (Meher et al., 2006). Not only can biofuels replace the impending loss of fossil fuels, it also has environmental benefits such as a lesser greenhouse gas emissions when compared to fossil fuels. The cultivation of plants as a result of biofuel production also sequestrates carbon dioxide in the atmosphere (Slade and Bauen, 2013).

Biodiesel, a biofuel, is produced by transesterification process were oil is mixed with alcohol in the presence of a catalyst. The oil could be from canola, peanut, corn, animal fat, rapeseed, palm, soybean and waste cooking oil (Singh et al., 2014). Other raw materials that gained importance as potential feedstock for biodiesel production are karanja, rubber plant, tobacco, jatropha, mahua, rice bran, animal fats and more 
recently, microalgae (Borugadda and Goud, 2012). Microalgae is currently considered to be the most feasible alternative since it has a higher photosynthetic yield (3-8\%) compared to other plants (less than 1\%) that makes them grow faster (1-3 doublings per day) (Slade and Bauen, 2013) (Alam et al., 2012), sequestrate carbon dioxide much better, and accumulate lipid yield of up to 50\% (Spolaore et al., 2006). Moreover, microalgae can grow in arid lands, swamps, and saline or fresh water which makes them a non-competitor in land utilization against others crops whether for fuel or food production (Alam et al., 2012). Also, microalgae are a tough species that makes them tolerant severe environmental conditions where losses due to calamities such as floods and storms are negligible when compared to other terrestrial plants (Najafi et al., 2011).

The downside of biodiesel production from microalgae are the cost associated with microalgae cultivation, lipid extraction and oil purification (Raslavičius et al., 2014). To minimize costs associated with algal biodiesel production, certain processes and catalyst were evaluated. The usual catalyst for biodiesel production are homogenous alkali catalyst like $\mathrm{NaOH}$ or $\mathrm{KOH}$ (Lam et al., 2010). However, there is cost associated with its separation from the final product and full recovery are always a challenge. A few studies have recommended the use of synthesized catalyst but they are either expensive or underperforming (Sharma et al., 2011; Díaz and Borges, 2012). Synthesized catalysts had been made by using metal oxides such as calcium oxide and magnesium oxide (Zabeti et al., 2009), metal complexes (Tariq et al., 2012), and metal hydroxides (Wang et al., 2013). The ease of separation and more cost efficient downstream processes were highlighted in these studies. However, the formation of the three phase system proved to be a huge factor in leading to low FAME yields (Zabeti et al., 2009). This study presents the synthesis of a catalyst that promises to be cheap, easier to prepare and can deliver biodiesel with acceptable methyl ester yields.

\section{Materials and Methods}

\section{Materials}

Pumice powder was purchased from Sigma Aldrich Chemical Corporation, USA. The microalgae was provided by the Food Protein Research and Development Center (FPRDC) of Texas A \& M University (TAMU). The microalgae was in dried colletized form and are labelled to be $95 \%$ Chlorella vulgaris with 8-10\% moisture. Other chemicals and reagents used in the oil extraction, transesterification and analysis of biodiesel were purchased from Sigma Aldrich Chemical Corporation, USA and VWR Chemical Corporation, USA.

\section{Preparation of Catalyst}

Pumice powder was used in this study as the support for the synthesis of metalpumice catalyst. Pumice was initially dried in an oven at $120^{\circ} \mathrm{C}$ for 3 hours after which it was ion exchanged by impregnation method with an alkali solution for 24 hours. The alkali solution varied in terms of concentration and kind. There were three kinds of alkali aqueous solutions used in this study namely $\mathrm{KOH}, \mathrm{NaOH}$ and $\mathrm{LiOH}$. Concentrations of the solutions also varied from $0.5 \mathrm{~N}$ to $4.0 \mathrm{~N}$. After ionic exchange, the pumice was recovered and dried again in an oven at $120{ }^{\circ} \mathrm{C}$ for another 3 hours. The subsequent product was then kept in a tightly sealed jar ready for evaluation and transesterifcation processes. 


\section{Catalyst Characterization}

Pumice and metal-loaded pumice (K-pumice, Li-pumice, and Na-pumice) were characterized using Hammett indicators, X-ray Diffraction (XRD), Scanning Electron Microscopy (SEM) and Infrared Spectroscopy (IR).

The Hammett Indicators measured base strength of the catalysts and its base total amount. The base strength is measured with $\mathrm{pH}$ of aqueous solution saturated with catalyst $(20 \mathrm{~g} / 50 \mathrm{ml})$. Base total amount was measured by titrating $0.1 \mathrm{~N}$ Benzoic Acid in Benzene to the mixture of $1 \mathrm{~g}$ catalyst sample in $20 \mathrm{ml}$ Benzene with $1 \mathrm{ml}$ indicator solution (phenolphthalein in ethyl alcohol).

The SEM and EDS analysis was done with the JEOL JSM-7500F, an ultra-high resolution field emission scanning electron microscope (FE-SEM) equipped with a high brightness conical FE gun and a low aberration conical objective lens. The catalysts samples were loaded into the equipment in one batch. The samples were labelled each prior loading into the equipment. For each analysed sample, at least three areas for were chosen purposely with images taken thereafter ranging from $1 \mu \mathrm{m}$ to $100 \mathrm{~nm}$. The best image taken from each sample was presented in these paper. The EDS analysis were then done right after the images were taken. Sites in the surface of the samples that were evaluated by the EDS were also purposely chosen.

The IR measurements were performed with the Shimadzu IR Affinity-1 equipment. The $\mathrm{KBr}$ pellet technique was used in determining IR spectra of the samples at room temperature. The range was adjusted at $600-4500 \mathrm{~cm}^{-1}$, with 300 scans and $4 \mathrm{~cm}^{-1}$ resolution.

\section{Transesterification Reaction}

The transesterification experimental runs started with the oil extraction from the milled microalgae. The extraction was done via Soxhlet facility whereby $500 \mathrm{~g}$ of microalgae was loaded per batch and the extracting solvent was $250 \mathrm{ml}$ of $\mathrm{n}$-hexane. The whole extracting procedure was done after about 20 passes which took 6 hours. After the distillate was cooled to room temperature, it was transferred to the rotary evaporator to separate the algal oil from n-hexane. The algal oil was then further purified using the methods described by Tyagi et al. (2012).

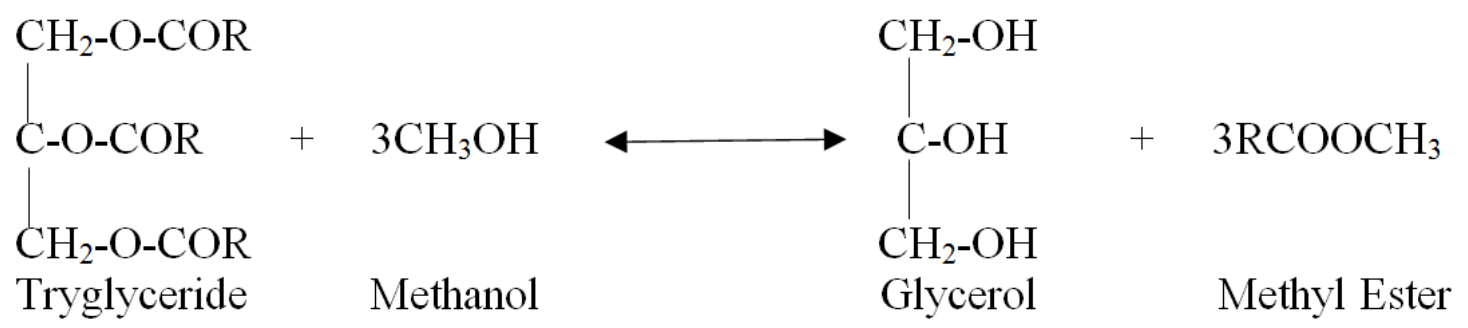

Figure 1. The transesterification reaction

The transesterification reactions (as described in Figure 1) were carried out in a 125 $\mathrm{ml}$ three-neck glass flask equipped with a stirrer, a water cooling condenser and an electric jacket with thermocouple. Five grams of initially extracted and purified algal oil was placed into the flask and was heated in the range $40-60{ }^{\circ} \mathrm{C}$ while stirring. After the oil has reached the desired temperature, methanol and the catalyst where carefully added to the system. The kind of catalyst (Li-pumice, K-pumice, Na-pumice), amount 
of methanol (methanol to oil ratio 6:1-22:1) and catalyst loading varied in each transesterification procedure (5-20\% by weight of algal oil). The reaction time for each transesterification process was also varied from 30 minutes to four hours. After transesterification, the mixture was filtered to separate the catalyst from the liquid. The liquid mixture was then subjected to the rotary evaporator to remove methanol. It was then placed in a separatory funnel and laid to rest for six hours before removing the glycerine that settled at the bottom of the funnel. The remaining liquid, which is presumed to be mostly biodiesel, is washed with hot water $\left(60-80{ }^{\circ} \mathrm{C}\right)$ to dissolve and separate soap formed during the reaction. The water is removed using again the separatory funnel. The washed biodiesel was then weighed and a sample was collected and loaded to the Shimadzu GC-2010 with Zebron ZB-5MS column for qualitative analysis. Meanwhile, the separated catalyst from the transesterification reaction was washed with methanol, dried and calcined for 12 hours in a temperature of $300{ }^{\circ} \mathrm{C}$. It was again regenerated by ion exchanging in a $1.0 \mathrm{~N}$ alkali aqueous solution and placed in a $120^{\circ} \mathrm{C}$ for 3 hours. The regenerated catalyst was then left to cool in a desiccant where it was later transferred in a cool dry jar for storage.

\section{Analysis}

The fatty acid methyl ester (FAME) yield of biodiesel was calculated by its weight in the crude biodiesel in relation to the weight of oil extracted from the algal biomass. The composition of FAME contained in the washed biodiesel was analysed by GC-MS. The biodiesel samples collected were dissolved in dichloromethane in the ratio 1:4 and loaded into the GC trey. The carrier gas used was helium and the injection volume of the sample was set at $1.0 \mu \mathrm{l}$ at an injection temperature of $180{ }^{\circ} \mathrm{C}$. The temperature program of the GC-MS was initially set at $50^{\circ} \mathrm{C}$ held for $5 \mathrm{~min}$, increased to $250{ }^{\circ} \mathrm{C}$ at 5 ${ }^{\circ} \mathrm{C} / \mathrm{min}$, and held at $250^{\circ} \mathrm{C}$ for $10 \mathrm{~min}$. The relative weight composition of the sample was determined using methyl stearate as the standard. Data gathered from all experiments were carefully recorded and were done in triplicate.

\section{Results and Discussion}

\section{Catalyst Characterization}

The results of Hammett Basicity Test (Table 1) suggested that considerable difference in base total amount can be observed in between catalyst that were impregnated in $0.5 \mathrm{~N}$ solutions and $1.0 \mathrm{~N}$ solutions. As concentration of contact solution increases, so is the base total amount but of negligible margins for solutions with concentrations more than $1.0 \mathrm{~N}$. Base strength is almost unanimously the same for contact solutions $1.0 \mathrm{~N}$ and above. K-pumice generally is more basic and has higher number of basic sites while Li-pumice has the least.

Table 1. Base Strength and Base Total Amount of Synthesized Catalysts

\begin{tabular}{c|c|c|c}
\hline Catalyst & $\begin{array}{c}\text { Contact } \\
\text { Solution }(\mathbf{N})\end{array}$ & Base Strength & $\begin{array}{c}\text { Base total amount } \\
(\mathbf{m ~ m o l} / \mathbf{g})\end{array}$ \\
\hline \multirow{3}{*}{ Li- pumice } & 4.0 & 12.1 & 50 \\
& 2.0 & 12.1 & 47 \\
& 1.0 & 11.7 & 33 \\
& 0.5 & 11.3 & 2 \\
\hline
\end{tabular}




\begin{tabular}{c|c|c|c}
\hline \multirow{3}{*}{ Na-pumice } & 4.0 & 12.4 & 56 \\
& 2.0 & 12.4 & 55 \\
& 1.0 & 12.2 & 47 \\
\hline \multirow{3}{*}{ K-pumice } & 0.5 & 11.9 & 7 \\
\hline & 4.0 & 12.6 & 62 \\
& 2.0 & 12.6 & 60 \\
& 1.0 & 12.5 & 55 \\
\hline
\end{tabular}

The EDS values (Table 2) are relative weight percentages of the elements found in the surface of the catalysts evaluated. The catalysts presented in the table are Na-pumice and K-pumice contacted with a $1.0 \mathrm{~N}$ solution. The Li-pumice was not included upon EDS evaluation since the equipment could not detect spectra of elements lighter than carbon which included lithium. It was also assumed that the same values will transpire for catalysts that were contacted with solutions greater than $1.0 \mathrm{~N}$ since their base strength and base total amount are relatively similar to those catalysts contacted with $1.0 \mathrm{~N}$ solution. In retrospect, the value of base total amount indicates the quantity of metal impregnated in the catalyst support (Galadima and Muraza, 2014).

Table 2. Relative weight percent composition of pumice and metal impregnated pumice

\begin{tabular}{c|c|c|c}
\hline Element & Blank & Na & K \\
\hline $\mathbf{C}$ & 15 & 14.5 & 14.5 \\
$\mathbf{O}$ & 59 & 58 & 58 \\
$\mathbf{S i}$ & 4 & 4 & 4 \\
$\mathbf{A l}$ & 18 & 17.5 & 17.5 \\
$\mathbf{K}$ & 1.5 & 1.5 & 3.5 \\
$\mathbf{N a}$ & 1 & 3 & 1 \\
Others & 1.5 & 1.5 & 1.5 \\
Total & 100 & 100 & 100 \\
\hline
\end{tabular}

As noted in Table 2, the blank pumice is predominantly composed of silicon, aluminum, carbon and oxygen being it a volcanic rock that is mostly silica and alumina. It initially has $1 \%$ sodium and $1.5 \%$ potassium. By impregnating it with a metal hydroxide solution, the relative weight percentage of the element is increased by $2 \%$, thus the increase in the basic sites of the synthesized catalyst. On this presumption, the Li-pumice (with $1.0 \mathrm{~N}$ or above contact solution) may likely also to have $2 \%$ lithium in its over-all weight composition. The elements that listed as others are magnesium, calcium, palladium, iron, nickel and nitrogen.

The FTIR readings (Figure 2) of the selected catalysts displayed there absorbance from 600 to $4000 \mathrm{~cm}^{-1}$. The catalysts that were evaluated was limited to 6 since the objective is to demonstrate the difference in the infrared spectrum of absorbance in pure pumice, pumice impregnated with different metals, and pumice impregnated with different concentrations of alkali aqueous solution. 


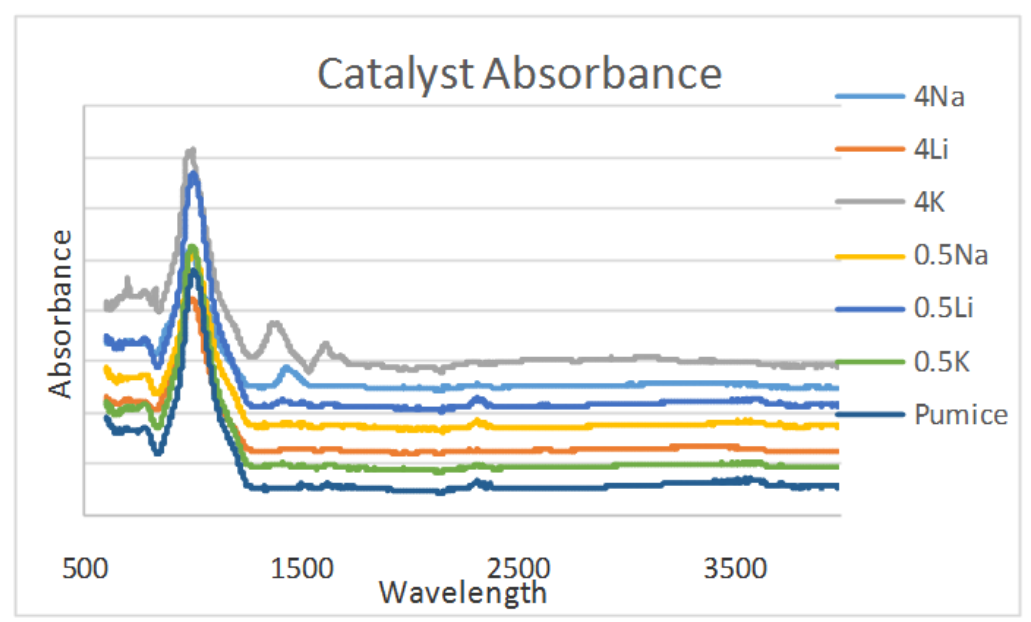

Figure 2. Catalyst absorbance of pumice and selected synthesized catalysts

The peaks at 600 and $800 \mathrm{~cm}-1$ in the FTIR spectrum of the pumice and metal loaded pumice may have resulted from the $\mathrm{Si}-\mathrm{O}$ bending strength vibrations of the amorphous quartz which constituted the structure while the strong peak around 1000 $\mathrm{cm}^{-1}$ may have resulted from Si-O stretching vibrations (Selli and Forni, 1999). Pumice is predominantly composed of $\mathrm{SiO}_{2}(70 \%)$ and $\mathrm{Al}_{2} \mathrm{O}_{3}(15 \%)$. The noticeable difference on the FTIR spectrum in the strongest reactive catalyst (K-pumice contacted with $1.0 \mathrm{~N}$ $\mathrm{KOH}$ solution) and the weaker ones are the peaks detected between 1300 and 1600 $\mathrm{cm}^{-1}$. According to E. Selli et al. (Selli and Forni, 1999), the peak can be attributed to the Metal-O bond structure vibration that was formed in the surface of the pumice during the activation of the catalyst. Such peaks may not have been present in pumice that had been contacted in lower concentration solutions since the metals $(\mathrm{K}, \mathrm{Li}, \mathrm{Na})$ may have been embedded in the pores and not enough ions was able to have been adsorbed in the surface. The peaks are also noticeable but not as quite pronounced in the Na-loaded pumice (with $4.0 \mathrm{~N}$ as contact solution). The peak that could be observed around $2400 \mathrm{~cm}^{-1}$ for all the catalyst sampled pointed out the $-\mathrm{OH}$ stretching vibrations of the water (moisture) which was adsorbed by the sample from the outside environment (Selli and Forni, 1999).

The SEM images (Figure 3) were taken out of the selected three kinds of catalyst and the blank pumice. All images were taken to almost the same resolution and magnification for efficient and proper comparison (see scale $=1 \mu \mathrm{m})$. It can be noted that the pure pumice has mostly rough surfaces and orifices which are ideal for metal catalyst impregnation.

Shown also in an isolated case is a smooth surface with the absence of anything attached to it. For pumice impregnated with metals, the surfaces clearly has some particles that can be observed. The images though would be a bit imprecise to judge the differences on the appearance of the particles attached on the surfaces of pumice support with different metal impregnations. The images that were taken were just plainly made to observe what is in the surface of the impregnated pumice and to see how it is synchronized. Eminent in the images taken are the wavy-like material on the surface of K-pumice and the long and crystalline in shape (resembling fine broken glasses) in the surface of Na-pumice. 


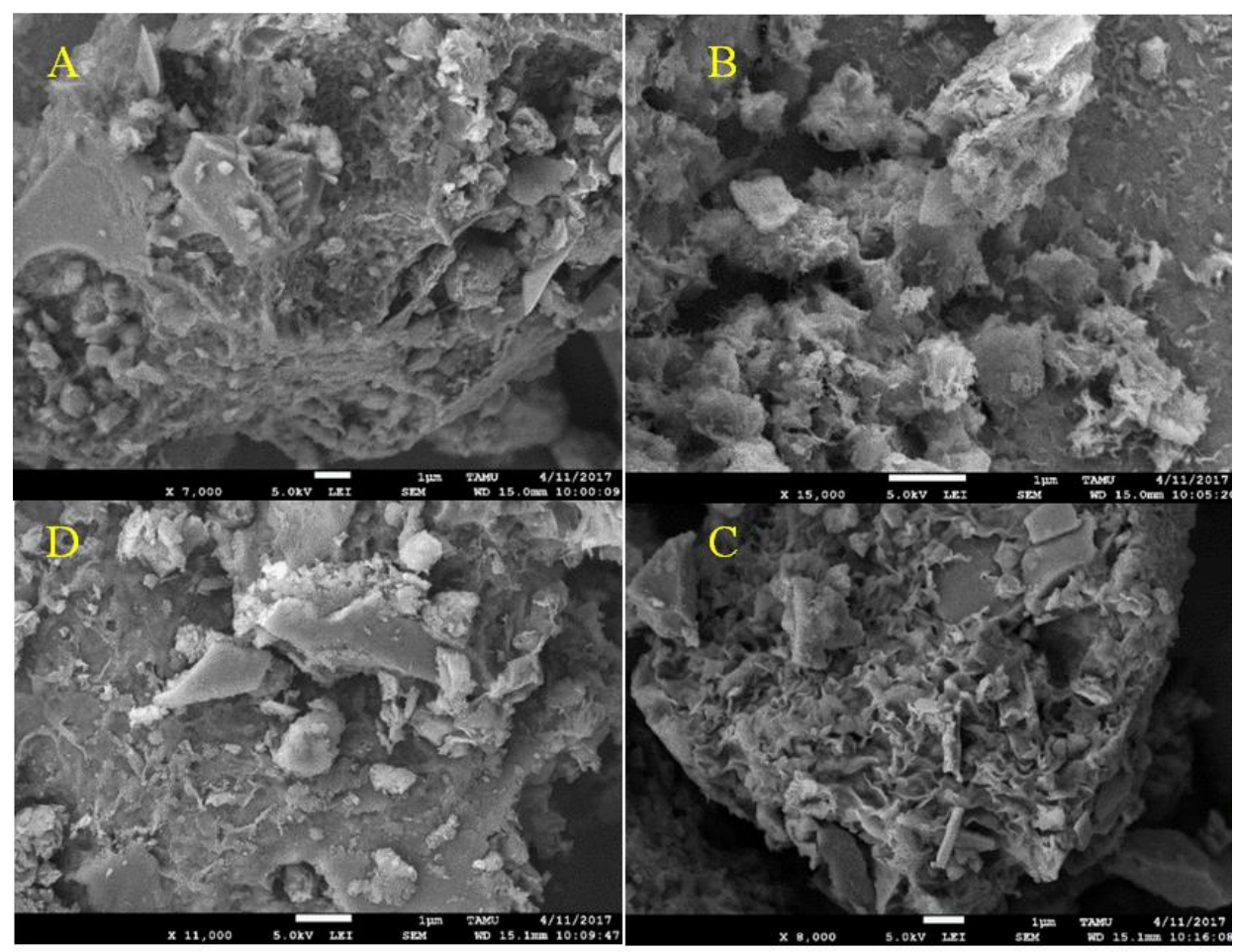

Figure 3. SEM images of pumice and metl-impregnated pumice. Clockwise from upper left: a) Pure pumice powder; b)Na-pumice; c) K-pumice ; d) Li-pumice

\section{Transesterification Process}

The process parameter that was firstly investigated was the concentration of the contact solution. With the other variables fixed at 20\% catalyst load, 18:1 methanol oil ratio, reaction temperature at $60{ }^{\circ} \mathrm{C}$, and reaction time equal to 2 hours, it was observed that K-pumice and Na-pumice with contact solutions $1.0 \mathrm{~N}$ to $4.0 \mathrm{~N}$ gave the best FAME yields (see Figure 4a). K-pumice had peaked at 77\% FAME yield when the concentration of contact solution is $1.0 \mathrm{~N}$ and the same yield have been recovered when the concentration of contact solution had been increased up to 4.0N. Na-pumice also had about $75 \%$ FAME yield at the same process conditions and just slightly increased to $76 \%$ when contact solution is increased up to $4.0 \mathrm{~N}$. Li-pumice had about $5 \%$ lower FAME yield as compared to the other two catalysts ion exchanged in the same concentration of contact solution.

During shorter reaction times, it is observed that K-pumice had a better FAME yield than Na-pumice and that the FAME yield gap between K-pumice and Li-pumice becomes larger. This phenomena maybe attributed to the difference in solubility of the three metals in methyl alcohol, with potassium to be the most soluble and lithium to be the least (Gryglewicz, 2000). Nevertheless, it is observed that the optimum contact solution for all catalyst is $1.0 \mathrm{~N}$. It is thru this concentration where the possible highest FAME yield was achieved for K-pumice and the curves plotted in Figure 4 for the other catalysts suggested it to be the most optimum. 


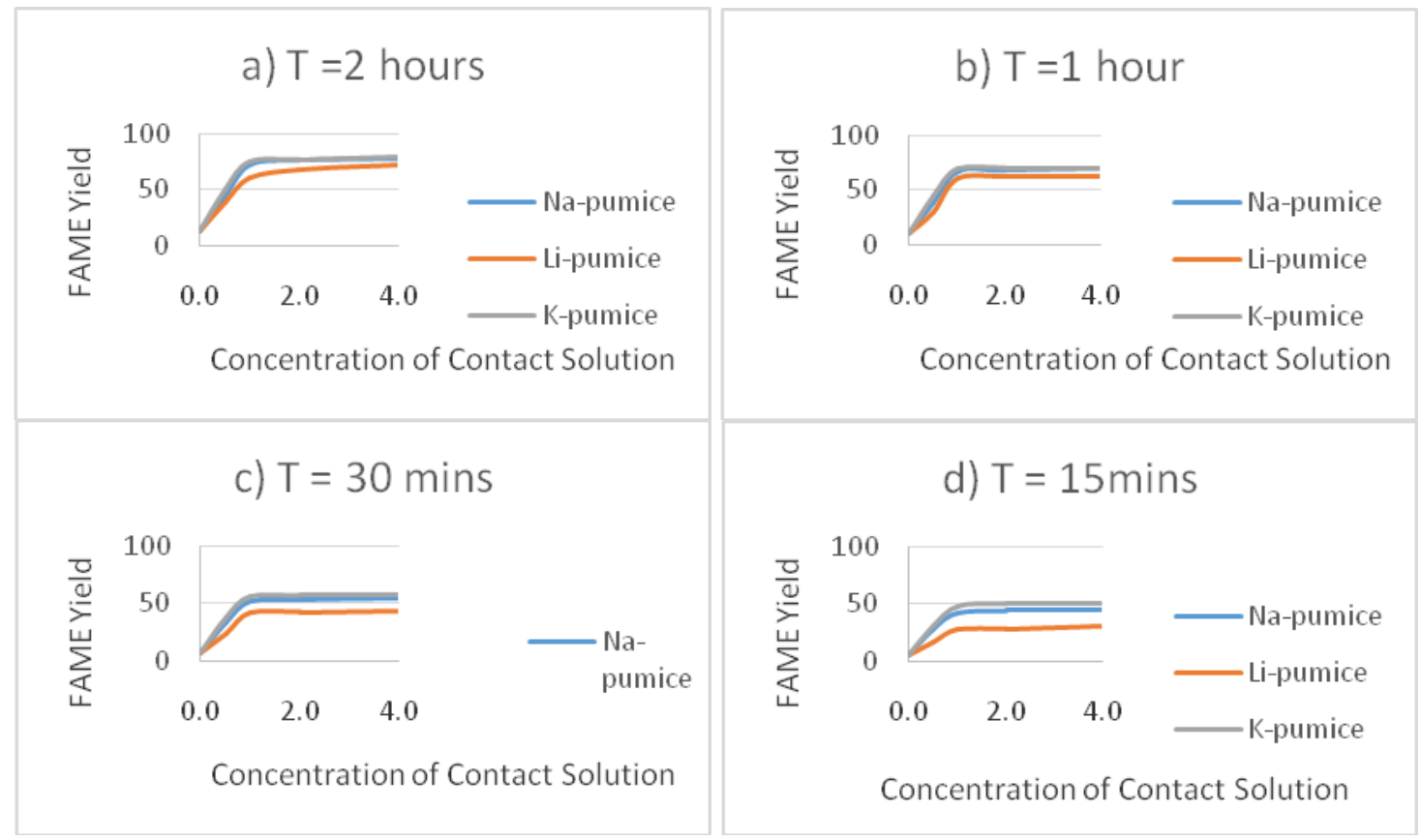

Figure 4. Process performance in terms of FAME yield of catalysts impregnated with different concentrations of contact solution at different reaction temperatures.

When the investigation was focused upon the optimum reaction time (Figure 5), the other process parameters were fixed at methanol to oil ratio at $18: 1$, reaction temperature equal to $60{ }^{\circ} \mathrm{C}$, catalyst load at $20 \%$ and the catalysts used were those contacted with $1.0 \mathrm{~N}$ solution. Both Na-pumice and K-pumice achieved the optimum FAME yield (75-77\%) after 2 hours of transesterification while Li-pumice still has an improved FAME yield after 4 hours. The best yield however that was acquired in the setup was that of K-pumice just after 2 hours of transesterification.

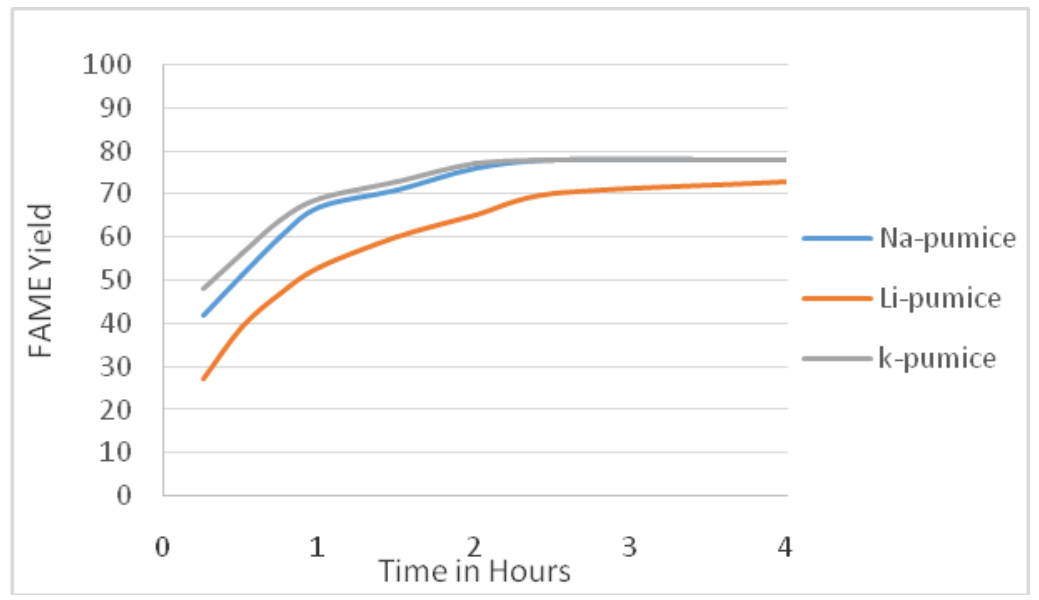

Figure 5. Influence of reaction time on the FAME yield using different types of catalysts

In the investigation of the optimum catalyst load (Figure 6), methanol to oil ratio (Figure 7), and reaction temperature (Figure 8), the catalysts used were limited to that 
contacted with $1.0 \mathrm{~N}$ solution. The other synthesized catalysts were not used in these experiments since it was proven earlier that the optimum concentration of contact solution is $1.0 \mathrm{~N}$. Also, the reaction time in these investigations were set at 2 hours.

The optimum catalyst load that was observed during these transesterification reactions was $10 \%$ for all the kinds of catalyst (see Figure 6). As with the data presented earlier, it had been noted that Li-pumice performed the least while K-pumice slightly fared better than Na-pumice. The methanol to oil ratio and reaction temperatures on these catalyst load optimization were set at $18: 1$ and $60{ }^{\circ} \mathrm{C}$, respectively.

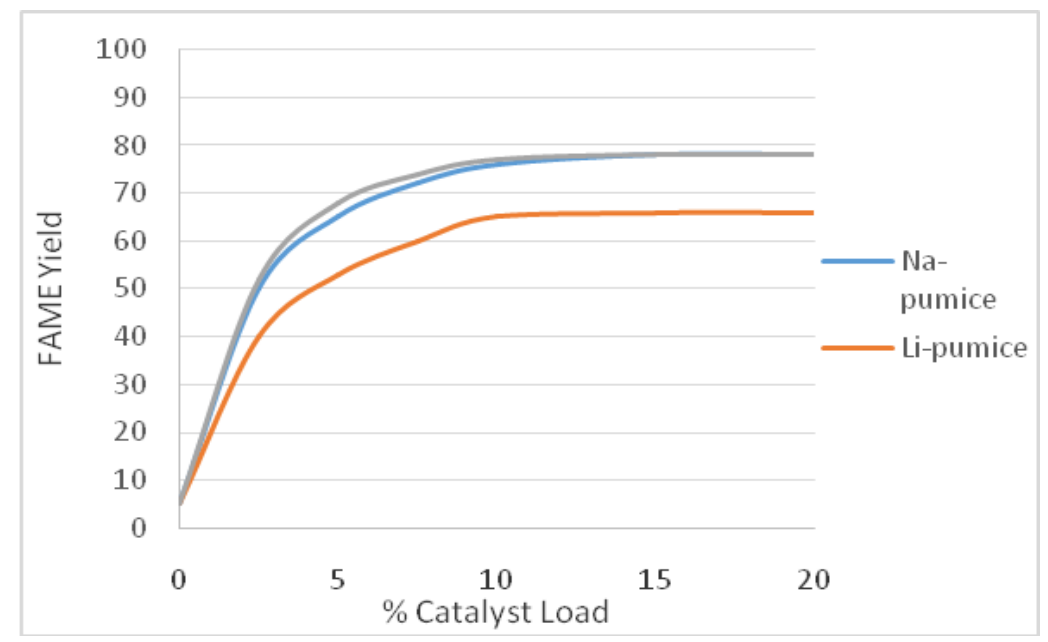

Figure 6. Influence of catalyst loading on the FAME yield using different types of catalyst

As far as the analysis on the methanol to oil ratio was concerned, the experiments showed that the optimum value is 18:1 (see Figure 7). Increasing the amount of methanol beyond that does not seem to increase the FAME yield of the reaction. Even though the optimum ratio in transesterification experiments is 6:1 when the catalyst is homogenous and alkali in nature, the same ratio using the catalyst being used in these experiments can only give a maximum of 35\% FAME yield. It is most likely because of the three-phase system in the reaction that more alcohol should be introduced in order to hasten the reaction forward.

Finally, the investigation on the optimum reaction temperature only settled the long standing observation that the best reaction temperature of a transesterification process is the temperature just slightly below the boiling point of the reacting alcohol (Bharathiraja et al., 2014). Since methyl alcohol was used in these transesterification proceedings with a boiling point around $64.7^{\circ} \mathrm{C}$ at atmospheric conditions, the optimum reaction temperature obtained in these experiments were $60^{\circ} \mathrm{C}$ (see Figure 8). Having the reaction temperature above the boiling point of the alcohol can make it to evaporate, lessening the interaction of oil and alcohol for them to produce biodiesel.

The reuse of the synthesized catalyst in this study was also scrutinized. It is very important that the catalyst should be able to prove itself for reuse in order to justify its use economically. The experiments reused the catalyst that were earlier used in prior transesterification experiments. The investigation covered the reuse of the catalysts that were regenerated and those that were not. Regeneration is the term used in this study whereby the catalyst is being washed by methanol, dried, calcined and impregnated 
again in $1.0 \mathrm{~N}$ contact solution $(\mathrm{NaOH}, \mathrm{KOH}$, or $\mathrm{LiOH})$. Those that were not regenerated was just dried, calcined and used again on the next transesterification process. The process conditions in the reusability transesterification processes were the optimum as based on the earlier experiments.

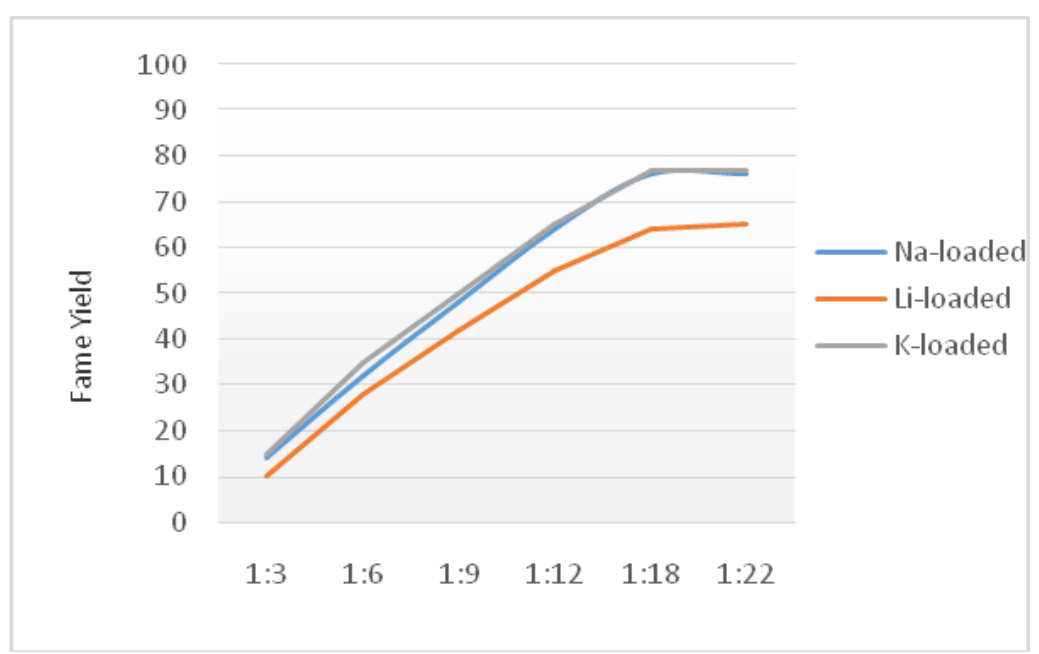

Figure 7. Influence of methanol to oil ratio on the FAME yield using different types of catalysts

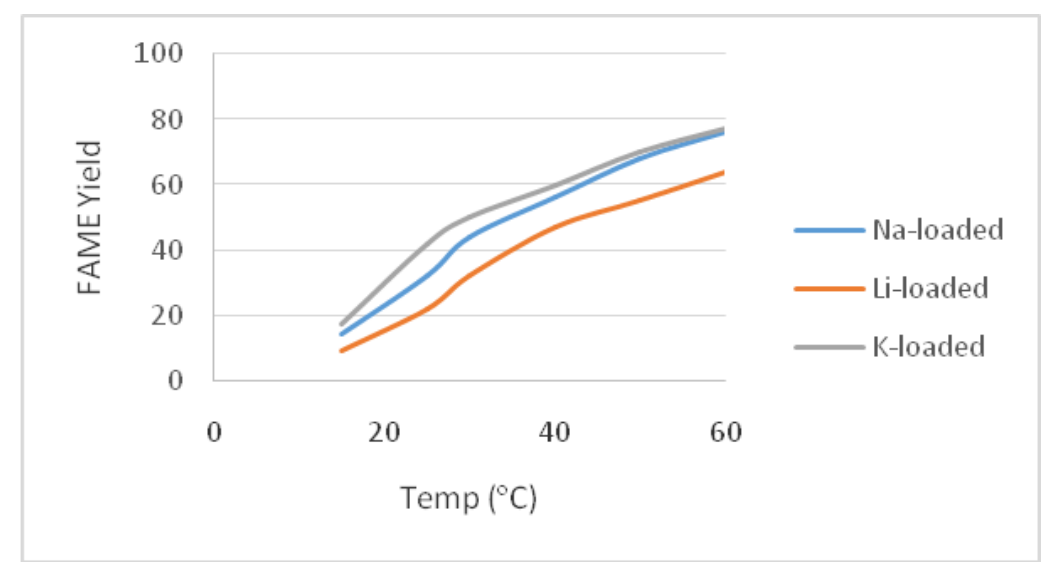

Figure 8. Influence of reaction temperature on the FAME yield using different types of catalysts

The reusability experiments discovered that without regeneration, the most effective number of reuse that the synthesized catalysts could do is just up to three uses (see Figure $9 a$ ). If it would be regenerated, the catalyst can be reused multiple times over without affecting its prior performance (Figure $9 b$ ). It is worth noting that blank pumice can be able to produce biodiesel even at a lower yield. It is most probable that the surface of the material has catalytic properties that can support transesterification reactions even if it was not impregnated at all by an alkali solution. Also, the data in Figure $8 b$ showed the resemblance of the curves by the three kinds of catalyst even when they are at different levels. It could indicate that the reusability can particularly be associated with the physical nature of the catalyst support which in this case is pumice. 


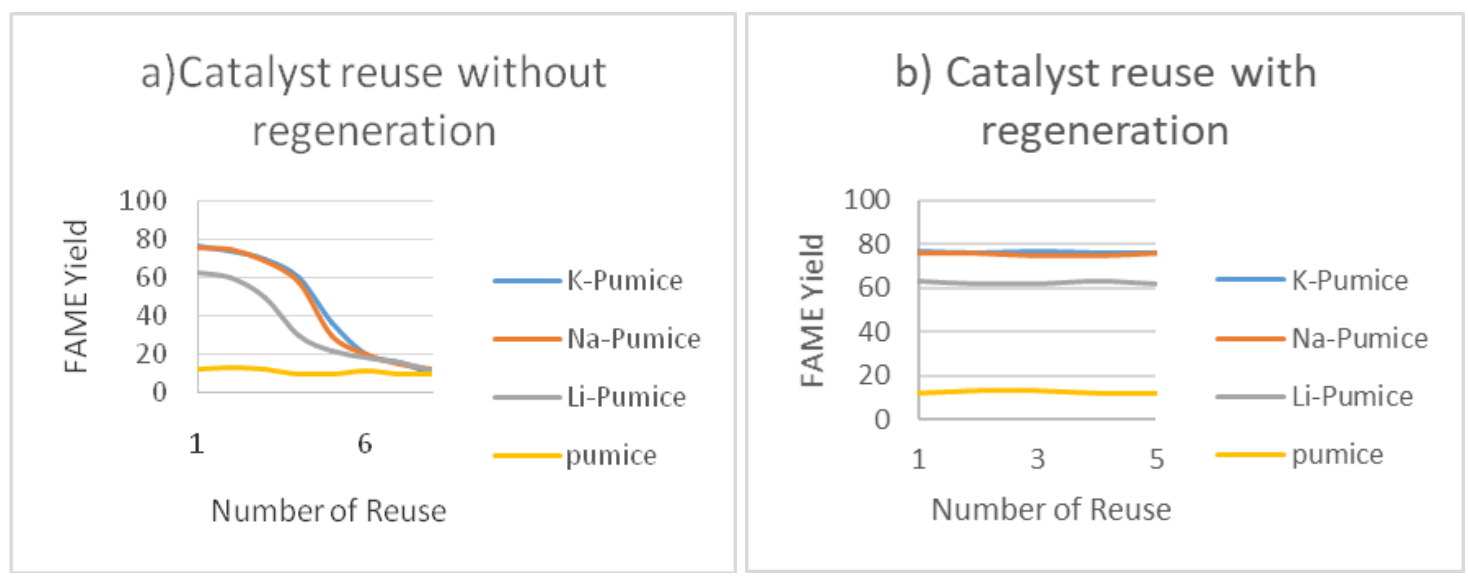

Figure 9. Reusability of the catalysts

\section{Conclusion}

The synthesized catalyst that was made by ion exchanging an alkali solution with pumice powder proved to be one of the better alternatives to the pre-existing catalysts in the production of biodiesel. The cheap cost of the catalyst support which is pumice, and the ease of preparation of the catalyst make it viable in transesterification processes. It was easily separated by filtration and was proven to be effective in reuse with regeneration. The best performing catalyst as far as FAME yield is concerned was $\mathrm{K}$ pumice, followed by Na-pumice and then Li-pumice. The optimum contact solution in the synthesis of the catalysts were $1.0 \mathrm{~N}$. The K-pumice catalyst was able to generate FAME yield of $77 \%$ from microalgae. The optimum process conditions to guarantee maximum FAME yield when using K-pumice as the catalyst are: reaction time $=2$ hours; reaction temperature $=60$; methanol to oil ratio $=18: 1$ and catalyst load $=10 \%$. The current FAME yield could still be improved by tapping to current technologies that are being used in transesterification reactions. It is strongly recommended that ultrasound and microwave technologies be incorporated to the current set-up since it may affect positively the yield of the resulting biodiesel. Also, it would be interesting if the synthesized catalyst in this study be tried for biodiesel production using other lipid source such as animal fat, waste vegetable oil, or others sources that are considered to be waste. Further investigation in catalyst synthesis using cheap materials not yet tried for biodiesel production will be encouraged.

Acknowledgement. The authors would like to thank the assistance of the three departments of TAMU, namely; Food Protein Research and Development Center (FPRDC), for their supply of microalgae that was given without a fee; the Materials Characterization Facility (MCF), for the assistance and use of the JEOL JSM-7500F responsible for the EDS and SEM analysis; and the Bioenergy Testing and Analysis Laboratory (BETA), for the use of the facility during the course of this research. Also, this project is indebted to the USAID STRIDE Program for funding the needs from all the materials consumed to the lease of various equipment that made this research possible. 


\section{REFERENCES}

[1] Alam, F., Date, A.,Rasjidin, R., Mobin, S., Moria, H., Baqui, A. (2012): Biofuel from algae-Is it a viable alternative? - Procedia Engineering 49: 221-227.

[2] Bharathiraja, B., Chakravarthy, M., Kumar, R., Yuvaraj, D., Kumar, P., Palani, S. (2014): Biodiesel production using chemical and biological methods - A review of process, catalyst, acyl acceptor, source and process variables. - Renewable and Sustainable Energy Reviews 38: 368-382.

[3] Borugadda, V. B., Goud, V. V. (2012): Biodiesel production from renewable feedstocks: Status and opportunities. - Renewable and Sustainable Energy Reviews 16(7): 47634784.

[4] Díaz, L., Borges, M. E. (2012): Low-quality vegetable oils as feedstock for biodiesel production using k-pumice as solid catalyst. Tolerance of water and free fatty acids contents. - Journal of Agricultural and Food Chemistry 60(32): 7928-7933.

[5] Galadima, A., Muraza, O. (2014): Biodiesel production from algae by using heterogeneous catalysts: Acritical review. - Energy 78: 72-83.

[6] Gryglewicz, S. (2000): Alkaline-earth metal compounds as alcoholysis catalysts for ester oils synthesis. - Applied Catalysis A: General 192(1): 23-28.

[7] Lam, M. K., Lee, K. T., Mohamed, A. R. (2010): Homogeneous, heterogeneous and enzymatic catalysis for transesterification of high free fatty acid oil (waste cooking oil) to biodiesel: A review. - Biotechnology Advances 28(4): 500-518.

[8] Meher, L. C., Vidya Sagar, D., Naik, S. N. (2006): Technical aspects of biodiesel production by transesterification - A review. - Renewable and Sustainable Energy Reviews 10(3): 248-268.

[9] Najafi, G., Ghobadian, B., Yusaf, T. F. (2011): Algae as a sustainable energy source for biofuel production in Iran: A case study. - Renewable and Sustainable Energy Reviews 15(8): 3870-3876.

[10] Raslavičius, L., Semenov, V., Chernova, N., Kopeyka, A. (2014): Producing transportation fuels from algae: In search of synergy. - Renewable and Sustainable Energy Reviews 40: 133-142.

[11] Selli, E., Forni, L. (1999): Comparison between the surface acidity of solid catalysts determined by TPD and FTIR analysis of pre-adsorbed pyridine. - Microporous and Mesoporous Materials 31(1-2): 129-140.

[12] Sharma, Y. C., Singh, B., Korstad, J. (2011): Latest developments on application of heterogenous basic catalysts for an efficient and eco friendly synthesis of biodiesel: A review. - Fuel 90(4): 1309-1324.

[13] Singh, B., Guldhe, A., Rawat, I., Bux, F. (2014): Towards a sustainable approach for development of biodiesel from plant and microalgae. - Renewable and Sustainable Energy Reviews 29: 216-245.

[14] Slade, R., Bauen, A. (2013): Micro-algae cultivation for biofuels: Cost, energy balance, environmental impacts and future prospects. - Biomass and Bioenergy 53(0): 29-38.

[15] Spolaore, P., Joannis-Cassan, C., Duran, E., Isambert, A. (2006): Commercial applications of microalgae. - Journal of Bioscience and Bioengineering, 101(2): 87-96.

[16] Tariq, M., Ali, S., Khalid, N. (2012): Activity of homogeneous and heterogeneous catalysts, spectroscopic and chromatographic characterization of biodiesel: A review. Renewable and Sustainable Energy Reviews 16(8): 6303-6316.

[17] Tyagi, K., Soban Kumar, D., Sundaresan, A., Arumughan, C. (2012): A novel process for physically refining rice bran oil through degumming. - Advances in Applied Science Research 3(3): 1435-1439.

[18] Wang, B., Li, S., Tian, S., Feng, R., Meng, Y. (2013): A new solid base catalyst for the transesterification of rapeseed oil to biodiesel with methanol. - Fuel 104: 698-703.

[19] Zabeti, M., Wan Daud, W. M. A., Aroua, M. K. (2009): Activity of solid catalysts for biodiesel production: A review. - Fuel Processing Technology 90(6): 770-777. 